\title{
A Critical Dialogue on Gender in the Aggregate, Gender in the Individual, and a Theory of Politicized Context
}

Where does gender express itself politically? What does gender mean, in political terms, for women? Is it possible to study gender expressed in and by individuals, across the aggregate, without dissecting the methodological and normative assumptions of (at least part of) our subfield?

In this Critical Perspectives section, Nancy Burns and Jane Junn speak to these questions from distinctly different but intersecting viewpoints. Both understand that the political meanings of gender are rooted in power and powerlessness, in "systematic disadvantage and advantage" (Burns, p. 104), and that our task as scholars is to explicate "when social and political contexts can make gender relevant" (p. 105). Both scholars speak primarily to gender in these essays, but also reflect on race as well.

Nancy Burns considers gender in the aggregate and in the individual, and maps how the relationship between the two might be explicated through their interaction with a theorized political context. She delineates a framework for understanding when and under what conditions "politics enables gender to shape individuals' political actions and public opinions" (p. 119). Using Burns's essay as a starting point, Jane Junn cautions us that such a project will face inherent difficulties that result from the conjunction of methodology and normative assumptions that underpin the kind of research Burns advocates. Conceptions about the individual and assumptions of "equality of agency among individuals" (p. 125), Junn argues, not only obscure political inequalities imbedded in gender but also produce unintended consequences. 
Gender in the Aggregate, Gender in the Individual, Gender and Political Action

Nancy Burns, University of Michigan and Center for Advanced Study in the Behavioral Sciences

Square Pegs and Round Holes: Challenges of Fitting Individual-Level Analysis to a Theory of Politicized Context of Gender

Jane Junn, Rutgers University

\section{Gender in the Aggregate, Gender in the Individual, Gender and Political Action}

Nancy Burns, University of Michigan and Center for Advanced Study in the Behavioral Sciences

The literature on gender and political action comes in two formsone that is aggregate, sometimes institutional, and often centered historically, and one that is individual and largely focused on the here and now. We care about both, of course-about the social organization and deployment of gender and about what gender means in individual lives. In this essay, I argue that we should encourage these two kinds of analysis to engage each other more intimately. This engagement would give political scientists the tools to say more about when, for whom, and for which outcomes gender matters. The conversation would give us better ways to understand how context makes gender relevant.

I believe that gender is a property of collections of people and social systems. We care about it because it is about systematic disadvantage and advantage. In this essay, I am especially interested in thinking about tools for identifying the political contexts in which this disadvantage and advantage come to matter in individual lives.

Iris Young says that gender is not much about a "self-consciously, mutually acknowledging collective with a self-conscious purpose," that instead, gender is a "less organized and unself-conscious collective unity"

Kate Gallagher provided incredibly thoughtful research assistance for this essay. Support for her work was provided by the Center for Political Studies at Michigan and by the Miller Professorship. I want to thank Jane Junn for a fabulous conversation about how to improve the essay. Lisa Baldez, Karen Beckwith, and Christina Wolbrecht provided important, critical feedback. The Center for Advanced Study in the Behavioral Sciences gave me the space in my life - and the amazing library staff-to finish the essay. Of course, all of the mistakes and omissions are mine. 